\title{
Makrokosmos I: George Crumb'in Eserinde Gelişmiş Piyano Teknikleri
}

\section{Makrokosmos I: Extended Piano Techniques in George Crumb's Work}

\section{Barış Lütfi BÜYÜKYILDIRIM ${ }^{1}$ [D}

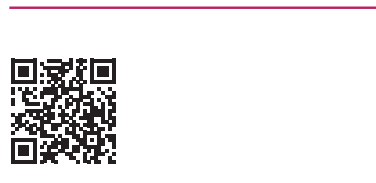

DOI: $10.26650 / C O N S 2020-0012$

'Dr. Öğr. Üyesi, İstanbul Üniversitesi Devlet Konservatuvarı, Müzik Bölümü, İstanbul, Türkiye

ORCID: B.L.B. 0000-0003-4861-1356

Sorumlu yazar/Corresponding author: Barış Lütfi Büyükyıldırım,

İstanbul Üniversitesi Devlet Konservatuvarı, Müzik Bölümü, İstanbul, Türkiye

E-posta/E-mail: barisbyildirim@gmail.com

Başvuru/Submitted: 14.09 .2020

ilk Revizyon/Revision Requested: 09.11.2020 Son Revizyon/Last Revision Requested: 27.11.2020

Kabul/Accepted: 27.11 .2020

Online Yayın/Published Online: 07.12.2020

Atıf/Citation: Buyukyildirim, B.L. (2020). Makrokosmos I: George Crumb'in eserinde gelişmiş piyano teknikleri. Konservatoryum Conservatorium, 7(2), 105-126. https://doi.org/10.26650/CONS2020-0012
Öz

Bu makalede, George Crumb'ın Makrokosmos I eserinde kullanılan 'gelişmiş piyano teknikleri'ne odaklanılmakta, bu tekniğin uygulanmasıyla ilgili bestecinin yorumlarını aktararak icra esnasında dikkat edilmesi gereken noktalara ışık tutmak istenmektedir. Eserin ithaf edildiği piyanist ve icracıların yorumlarıyla birlikte, yazar tarafından eserin icrası yoluyla edinilen çeşitli edimler aktarılmaktadır. Bestecinin müziksel geçmişi; sıradışı tınılar, numeroloji, notasyon, simetrik ilişkiler üzerinden incelenirken, eserde karşımıza çıkacak olan pizzicato, telleri susturarak çalma, glissandolar, doğuşkanlar, ses tahtasında çıkan perküsif efektler, zincir, yüksük, pena, ıslık ve vokal efektler gibi alışılagelmişin dışında olan çalış teknikleri, önerilen yöntem ve materyaller aktarılmıştır. Bu konuda David Burge'nin makale, kitap, söyleşilerinden faydalanılmıştır. Eserin performans notları öncelikli kaynak olmakla birlikte, Crumb hakkında yapılan çalışmalardan derlenen bilgiler ışığında, eserin icrası sırasında oluşabilecek teknik sorunlar aktarılmaktadır. Bu aktarımları, eserin çeşitli piyanolarda ve salonlarda icrası sayesinde edinilen öznel deneyimlerle, hem nota hem de performans üzerine yapılan teknik analizler vasıtasıyla elde edilen sonuç ve öneriler oluşturmaktadır. Böylelikle eseri yorumlamak için gerekli olan gelişmiş piyano tekniklerinde icra sırasında karşılaşılabilecek performansa ilişkin sorunlara yönelik bir öngörü sunmak amaçlanmıştır. Eserin nitelikli icrası için; eserin nota ve performans notlarının beraber değerlendirilmesi, işaretlemeler, esere uygun piyano seçimi, obje ve materyal seçimlerinde önem gerektiren hususlara dikkat çekilmekte; dramatik efektlerin icrasında özen ve amplifikasyonun önemi vurgulanmaktadır.

Anahtar Kelimeler: Crumb, Makrokosmos, Gelişmiş Piyano Teknikleri

\section{ABSTRACT}

This article purposes to elucidate the advanced piano techniques used in Crumb's Makrokosmos I and to illuminate features to be considered while working the piece. The study is primarily grounded in articles by David Burge, to whom the piece was dedicated, and the author's personal notes and experience of performing this work. The composer's musical context is discussed in terms ofnumeric symbolism, notation, and symmetrical relationships. Extended piano techniques have been examined through unusual sounds such as pizzicato, muted strings, glissandos, overtones, percussion effects on the soundboard, chain, thimble, plectrum, whistle, and 
vocal effects. Technical problems that may occur during the performance are also examined. Arguments are presented through subjective experiences attained from the performance of the work on various models of pianos and in diverse halls. The present study aims to offer insight into the performative problems of extended piano techniques. For the qualified performance of the work; it is recommended to work on the score and performance notes, appropriate piano selection, and the choice of suitable objects and materials for the skilled performance of this oeuvre. It also emphasizes the importance of the amplification of dramatic effects in the work's performance.

Keywords: Crumb, Makrokosmos, Extended Piano Techniques

\section{EXTENDED ABSTRACT}

The paper purposes to inform readers about the advanced piano techniques used in George Crumb's Makrokosmos I, one of the most significant piano repertoires of the twentieth century. It also attempts to illuminate features to be considered while working on the piece. Composers throughout history have created cycles of piano works; for example, Johan Sebastian Bach's Das Wohltemperierte Klavier, Frédéric Chopin's Etudes \& Preludes, Franz Liszt's Transcendental Etudes, Dmitry Shostakovich's Preludes \& Fugues, and Debussy's Preludes. Crumb's methods of writing a cycle comprise aspects such as prepared piano, plucking strings, laying a metal chain on strings, some vocal techniques, playing on keys, as well as amplification. These techniques were previously used by John Cage, Karl Heinz Stockhausen, and Henry Cowell. Advanced piano techniques involve using the inner and outer parts, strings, soundboard, steel features, and wood parts of the piano as instruments that supplement the sounds produced only by the keys. This technique incorporates the playing of various objects and materials, and even includes the use of human voices. Numerous works have been composed using this technique, which became quite widespread after the first half of the 20th century.

This study discusses the musical context of the composer in terms of numerology, notation, symmetrical relationships, and the composers who influenced him. It examines extended piano techniques through the analysis of personal performance notes and notations. Unusual sounds incorporated in the piece such as pizzicato, muted strings, glissandos, overtones, percussion effects on the soundboard, chain, thimble, plectrum, whistle, and vocal effects will be examined through the author's numerous performances of this work. Articles by David Burge, to whom the piece was dedicated, as well as books, interviews, and personal experiences, are referenced as sources for the present study. The study also examines potential technical problems that may occur during the performance of this oeuvre. The arguments or the study are posited through subjective 
experience attained through the performance of this work on various brands and models of pianos and in halls with differing acoustic conditions. The suggestions tendered in the paper are obtained through the analysis of the score as well as the performance notes, and the conclusions are derived from the performance of the piece.

The two sections of George Crumb's Makrokosmos are divided into three parts each, which are themselves sectioned into four segments meant to be played without interruption. Crumb designed the last four parts of the three divisions of the two sections as symbols: for example, in Volume I, piece number 4, "Crucifixus" is presented as a cross; piece number 8, "The Magic Circle of Infinity" is noted as circle; and piece number 12, "Spiral Galaxy" is displayed as a spiral. In this manner, Crumb connected this musical venture to the star signs of the Zodiac.

Each of the twelve fantasy pieces is labeled with a Zodiac sign of the zodiac and with the initials of someone born under that sign: a friend, colleague, family member, or respected composer. In both volumes, the pianist must not only to play in and out of the piano, but also whistle, sing, shout, and whisper in varied and specified ways. Singing is always notated only in the bass clef because the pianist-dedicatees of each volume are men; women may transpose pitches up an octave. Whistling is notated at an exact pitch; the whistling requirements in both volumes are demanding and most performers need to devote extended practice time to develop the range, breath control, and precise intonations to deliver an accurate and effective performance. For a competent performance of the work, it is recommended that performers work simultaneously on the musical and performance notes, paying attention to markings, selecting an appropriate piano for the piece, and choosing suitable objects and materials. The amplification of dramatic effects in the performance is also emphasized. While Crumb uses traditional musical, compositional, and pianistic techniques in Makrokosmos I; however, he also contrasts the conventional aspects with advanced piano techniques used by numerous composers of the period including John Cage and Henry Cowell. Therefore, performers must aim to improve their skills in the extended piano techniques required to interpret the work and to deliver an apposite performance. 


\section{Giriş}

Crumb Makrokosmos I eserinde geleneksel müziksel, bestecilik ve piyano tekniklerini kullanırken; aynı zamanda John Cage, Henry Cowell, Karl Heinz Stockhausen, Sofia Gubaidulina gibi dönemin pek çok bestecisinin kullandığı 'gelişmiş piyano teknikleri'ni de kullanmaktadır (Vaes, 2009). Bu teknikleri eserinde uygulamasının yansıra kaligrafik notasyonlarıyla alışıla gelmişin dışında bir çalma deneyimi sunarak icracılar tarafindan siklıkla tercih edilen bestecilerden biri olmuştur. Bununla beraber Makrokosmos I, gelişmiş piyano teknikleri ve farklı çalım stillerini gerektirdiği için çeşitli zorluk dereceleri olan bir eser olarak değerlendirilmektedir. Enstrümana ve piyano içindeki tellerin çalınmasına dair geliştirilen ve önerilen yöntemlerin öznel olarak deneyimlenmesi üzerinden icracılara çeşitli uygulama kolaylıkları ve oluşabilecek zorluklarla ilgili öngörüler sunmak amaçlanmaktadır. Bu konuda yapılan çalışmalarda (Burge, 1976; Matthews, 1982); icranın niteliğinin artırılması üzerine bestecinin performans notları ve notaları beraber değerlendirilmekte, kullandığ 1 notasyon tekniğ analiz edilerek diziler arasında kurulan ilişkiler incelenmektedir. Bu doğrultuda uygulanan teknikler yazar tarafından çeşitli salon ve piyanolarda denenmiş ve bu deneyimler sonucunda edinilen bilgiler makale çerçevesinde aktarılmıştır'. Crumb'ın müziksel karakterinde ve yazdığı eserlerde kullandığı gelişmiş piyano tekniklerinin uygulanmasının teknik çözümlemesi, eserin icrası için yeterli olmamaktadır. Aynı zamanda Crumb'ın müziksel niteliğine dair bir içgörü edinmek ve bestecinin müziksel geçmişine, etkilendiği eserlere, sembol ve kavramlara, şiirlere, kimi zaman kolajı andıran biçimde kullandığı diğer bestecilerin eserlerine dair bilgilere sahip olmak gerekmektedir. Onun böyle bir müziksel dokuya ulaşmasında çocukluk ve gençlik dönemlerindeki deneyimlerinin de etkisi olduğu düşünülmektedir². Müziksel gelişim sürecinde etkilendiği besteciler ve birbirinden farklı müziklerden esinlenerek oluşturduğu edimleri, müziksel karakteristik özelliklerine de yansımış; University of Michigan'daki çalışma-

1 Yazarın Makrokosmos I'i seslendirdiği konserlerin kayıtlarına https://www.barisbuyukyildirim.com/music linkinden erişilebilir.

2 George Henry Crumb, 1929 yılında West Virginalı müziksel bir aileden gelmektedir. Eğitimli bir klarinetist olan babasının notalarını okuyarak ve çalışarak büyümüștür. Crumb'ın müzik ve edebiyata tutkuyla bağlanması, hayatın gizemlerine, insanoğlunun doğayla olan ilişkisine karşı ömür boyu sürecek bir merak geliştirmesinde çocukluk tecrübeleri etkili olmuştur (Burge, 1990, s. 211). 9-10 yaşlarında besteler yapmaya başlayan Crumb, 14 yaşında piyano çalmaya başlamış, 1950'de Mason College of Music'te lisans eğitimini tamamladıktan sonra University of Illinois Champaign-Urban'da, Eugene Weigel ile yüksek lisans eğitimini almıştır. 1954-55 yılları arasında Berlin, Almanya'da Boris Blacher ile çalışmalar yapmış; 1959'da University of Michigan'da Ross Lee Finney ile doktora çalışmalarını tamamlamıştır. 
ları sırasında çok sayıda eser analiz etme, müziksel fikirler ve mimikleri sınıflandırma şansı bulmuştur. Besteci, yaptığı çalışmalarla birlikte kendi stilini oluşturacak dilini inşa etmeye de bu dönemlerde başlamıştır. En çok etkilendiği besteci olan Debussy öncelikli olmak üzere; Mahler, Bartok ve Webern'in müziğinde, Rilke ve İspanyol şair Lorca'nın şiirlerinde referanslar bulan bestecinin müziği, birbirine tezat, farklı müzik tarzlarının karşılaşmasından oluşmaktadır (Crumb, 1974; Duffie, 1998).

Shuffett'e göre (1979), Crumb, Mahler'in zaman kullanımı, (neredeyse Ives'ın stilinde olduğu gibi) diğer müziklerden alıntıları ve kozmik jestlerinden çok etkilenmiştir. Aynı zamanda Debussy'nin piyano müziğindeki pedal kullanımı, tınısal arayışı, tam ton gamından gelen simetrik strüktürlerini kendi müziğinde denemiştir. Webern'in $\mathrm{Op} .9 \mathrm{Ba}$ gatelle eserindeki yalın yazım stili, her küçük noktaya verilen önemin genel yapıyı oluşturması, Crumb'1 çok etkilemektedir. Yaylılardaki, col legno, pizzicato, sul ponticello, sul tasto ve doğuşkanlar gibi çeşitli efektlerin varyasyon zenginliğini kendi müziğinde kullanmak istemektedir (Shuffett, 1979, s. 549). Crumb, Bartok'un formundaki simetrik ilişkileri bir kemere benzetmekte (Pearsall, 2004) ve özellikle piyano eseri olan Out of Doors 'daki 'Nocturnal Sounds' parçasında yakaladığı doğal gece atmosferini çok etkileyici bulmaktadır (Shuffett, 1979 s. 415). Ars Nova' y1 andiran ve neredeyse eserleri bestelediği kadar zaman harcadığı belirtilen kaligrafik notasyonları, Schubert, Chopin, Bach, Lorca, Rilke gibi diğer bestecilerden alıntıları, sembolik-mistik tiyatral öğeleri işleyişi, gelişmiş piyano tekniklerini kullanımı (Crumb, 1974), klasik batı müziği dışındaki çeşitli türlere atıfları, doğa sesleri ve hatta elektronik seslerden esinlenen müziğiyle Crumb, dinleyici ve icracıların repertuvarlarında mutlaka yer alması gereken bestecilerden biri olagelmiştir.

Piyano için 5 Parça (1962), Night Music, soprano, piyano (çelesta), ve iki perküsyonist için Night Music I (1963), piyano ve keman için 4 Noktürn (1964), Madrigals (1965), flüt, klarnet, keman ve piyano için Eleven Echoes of Autumn (1966) eserleriyle birlikte, Amerika'nın en çok tanınan bestecilerinden biri haline gelmiştir (Henahan, 1975). 1970'lerde neredeyse bir kült figürüne dönüşen Crumb, soprano, çocuk soprano ve 7 enstrüman için Ancient Voices of Children (1970), yaylı dörtlüsü için Black Angels (1970), flüt, viyolonsel ve piyano için bestelediği Voice of the Whale (1971) ile dinleyicilerin hayal gücünü daha önce görülmemiş bir şekilde ele geçirecek nitelikte eserler üretmiştir (Schonberg, akt. Hanehan, 1975). 


\section{Makrokosmos I}

George Crumb, Makrokosmos I ve II ciltlerini, piyano için gelişmiş teknikleri ilk defa kullandığı 'Beş Piyano Parçası'ndan on sene sonra, 1972-73 arasında tamamlamıştır. Makrokosmos I, Amerikan modern müziğinin öncülerinden piyanist David Burge için yazılmıştır. Her cilt amplifiye edilmiş piyano için, 12 burç üzerine yazılmış olan 12 Fantazi-Parçasından (Twelve fantasy pieces after the Zodiac for amplified piano) oluşmaktadır (Crumb,1975). Crumb'dan önce de çeşitli besteciler 12 ve 24 parçadan oluşan setler yazmıştırlar; Bach'ın Das Wohltemperierte Klavier, Chopin'in Etüt ve Prelüdleri, Liszt' in Transandantel Etütleri, Shostakovich'in Prelüd ve Fügleri, Debussy'nin Prelüdleri bunlara örnektir. Crumb'ın besteciliğinde uyguladığ 'canlı' hayalgücünü sergileyen bölüm isimlerinden bazıları şöyledir; 'Pastoral (Atlantis Krallı̆̆ı'ndan, M.Ö. 10.000)', 'Hayalet-Noktürn: Stonehenge'in Kelt Rahipleri'. Bazı bölümler ise şekil 3, 4 ve 5'te görüldüğü üzere sembolik bir şekilde başlıklarıyla ilişkilendirilmiştir; 4 numara Crucifixus haç şeklinde notasyon edilirken, 8 numarada The Magic Circle of Infinity (Sonsuzluğun Büyülü Çemberi) dairesel ve 12 numara Spiral Galaxy'nin spiral olarak notasyona alınmıştır. Bunların dışında her bölüm bir burç ve o burçtan olan bir besteci, meslektaş ya da aile üyesine ithaf edilmiştir. 12 parçalık set, 3 bölüme ayrılmakta ve ara vermeden çalınmaktadır (Crumb, 1974).

Birinci Bölüm
1. Primeval Sounds (Genesis I) Cancer
2. $\quad$ Proteus Pisces
3. Pastorale (from the Kingdom of Atlantis, ca. 10.000 B.C.) Taurus
4. Crucifixus (SYMBOL) Capricorn

\section{İkinci Bölüm}

5. The Phantom Gondolier Scorpio

6. Night-Spell I Sagittarius

7. Music of Shadows (for Aeolian Harp) Libra

8. The Magic Circle of Infinity (Moto perpetuo) (SYMBOL) Leo 
Üçüncü Bölüm

9. The Abyss of Time Virgo

10. Spring-Fire Aries

11. Dream Images (Love-Death Music) Gemini

12. Spiral Galaxy (SYMBOL) Aquarius

Crumb, Makrokosmos I ve II'de piyano tuşları ve tellerin üzerinde çalma teknikleri d1şında, daha önce Stockhausen ve Cage'in kullanmış olduğu, pizzicato, amplifiye edilmiş piyano, metal bir zinciri tellerin üzerine yerleştirme, yüksükle çalma, sslık ve çeşitli vokal efektleri gibi postmodern teknikler kullanır.

Notalar, üçlü ve dörtlü ses dizilerinden oluşan akorlar ve daha büyük yapılar oluştururlar. $\mathrm{Bu}$ yapılardan meydana gelen pentatonik, tam ton ve oktatonik gamlar, eserin genel yapısını oluşturmaktadır (Bass, 1991, s. 3). 'Primeval Sounds' tüm eseri birleştirici bir rol oynar. 3 sesli dizilerin akor oluşturması hakkında 4 numaralı parça örnek gösterilebilir. Şekil 1'de gösterilen A ve B kısmının sonundaki doğuşkanlar birleştiklerinde tam ton gamını oluştururlar. Ayrıca A bölümündeki 7 akor, B bölümüne geçildiğinde artık 4'lüsüne transpoze edilerek karşımıza çıkar. Eserin genelinde artık 4'lü ilişkileri çok büyük rol oynar. Crumb kendisi pek onaylamasa da ya da önemsemese de (Shuffett, 1979, s. 426), yazılı glissandoların mesafesi en kalın la'dan başlar ve re diyez 3 ile biter. Bu mesafe bazı piyanolarda çelik geçişin bittiği yere denk gelmektedir. Ayrıca mi ve fa aksı da Makrokosmos'ta 6. parçada kullanılmıştır. Piyano için gelişmiş teknikte eser yazan Cowell gibi, diğer modern bestecilerin de bu aksı kullandığı bilinmektedir. 


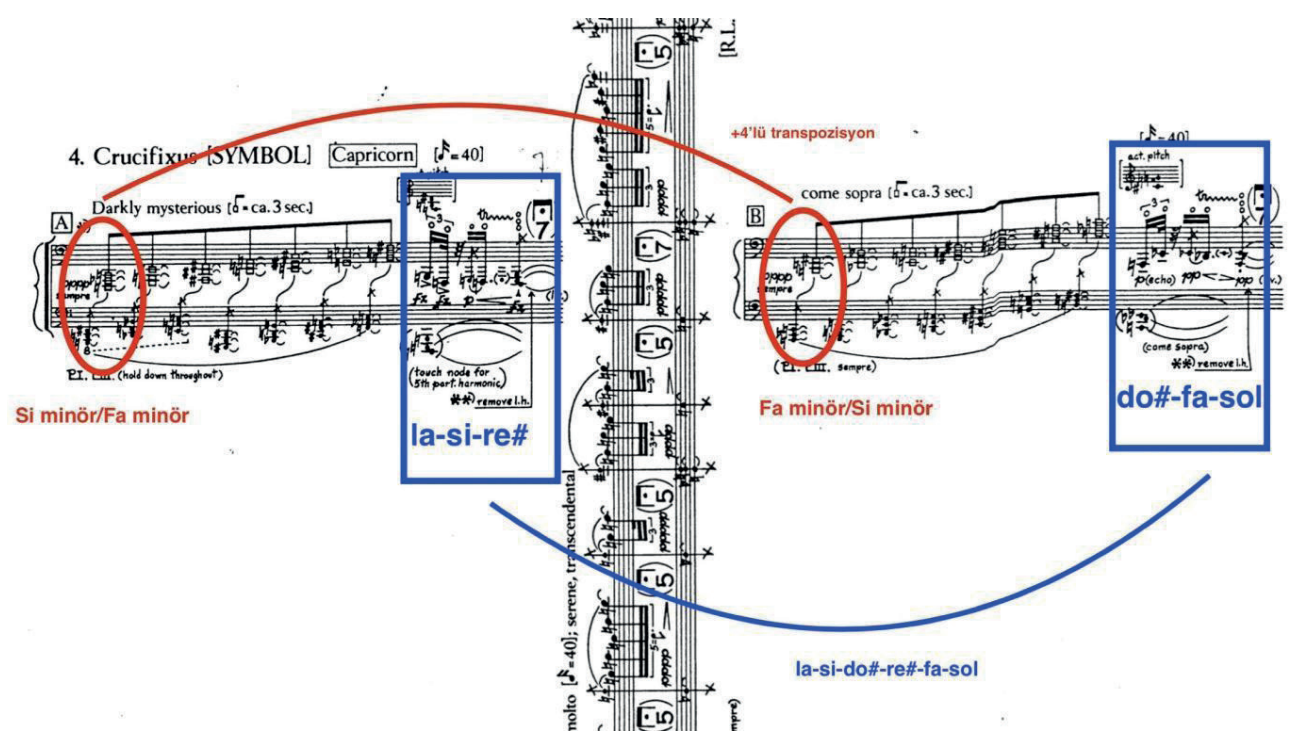

Şekil 1. 4 numaralı 'Crucifixus' (Crumb, 1974, s. 10)

Şekil 2'de görüldügü gibi Crumb'ın numeroloji ve asal sayılarla olan ilişkisi eser boyunca göze çarpmaktadır. Eserin ilk parçası kırmızı ile işaretlendiği şekilde 7 akorla başlamaktadır ve bunu mavi ile işaretlediği gibi 7 saniye süren bir fermata takip etmektedir. Aynı zamanda, eserin 4. ve 9. parçasında da benzer şekilde tekrar görmemiz mümkündür. Yeşille işaretli tam ton serileri 5 tekrardan sonra mavi ile işretlediği gibi 7 saniyelik bir tremolo ile devam etmektedir. 2 kere ve 5 kez tekrar eden tam ton gam 13 saniyelik bir fermatayla sonlanmaktadır. Bu parçada olan 14 notanın tekrar edilmesinden oluşan repetisyonlar, eserin diğer parçalarında da karşımıza çıkmakta; aynı zamanda yedilemeler ve beşlemeler sıklıkla karşımıza çıkmaktadır (Matthews, 1981, s. 47).

"Simetrik fikirler yapılandırıcı potansiyel barındırırlar. Doğru kullanıldıklarında müziği şekillendirmeye yardımcı olabilirler. Çoğu eserimde simetri bolca bulunur ve simetrik fikirlerin bütünlüğü sağlamayı kolaylaştırdığını düşünürüm. Kar tanelerinden kristal formasyonlarına, organizmalardan tüm bileşenlerine, doğanın içinde var olan bu simetriyi müziğe taşımanın doğal bir yöntem olduğunu düşünüyorum"3(Crumb, G. Aktaran. Shuffett, 1979, s. 487).

3 İngilizce'den çeviriler makale yazarı tarafından yapılmıştır. 


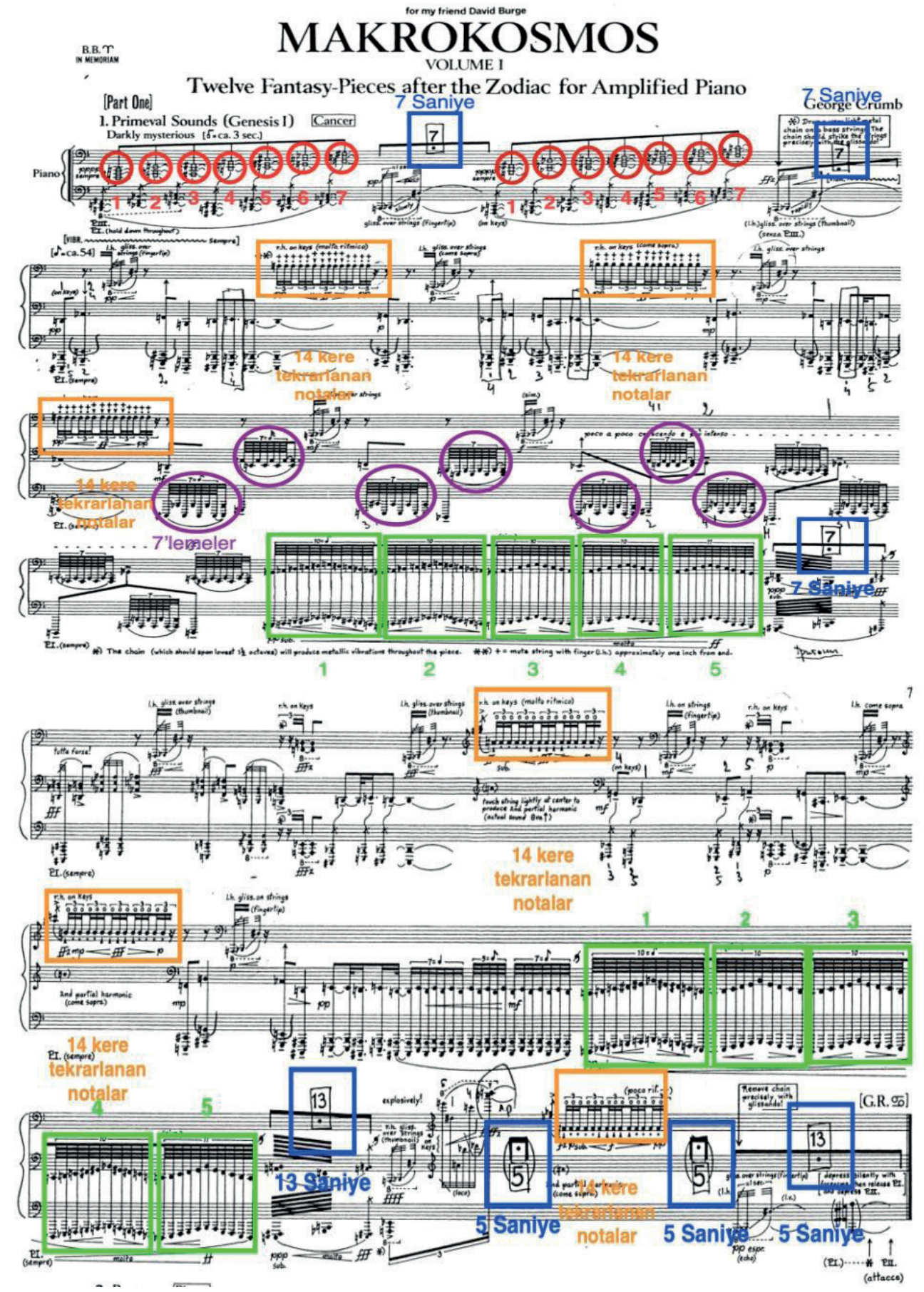

Şekil 2. 1. Primeval Sounds (Genesis I) (Crumb, 1974, s. 6-7) 
10

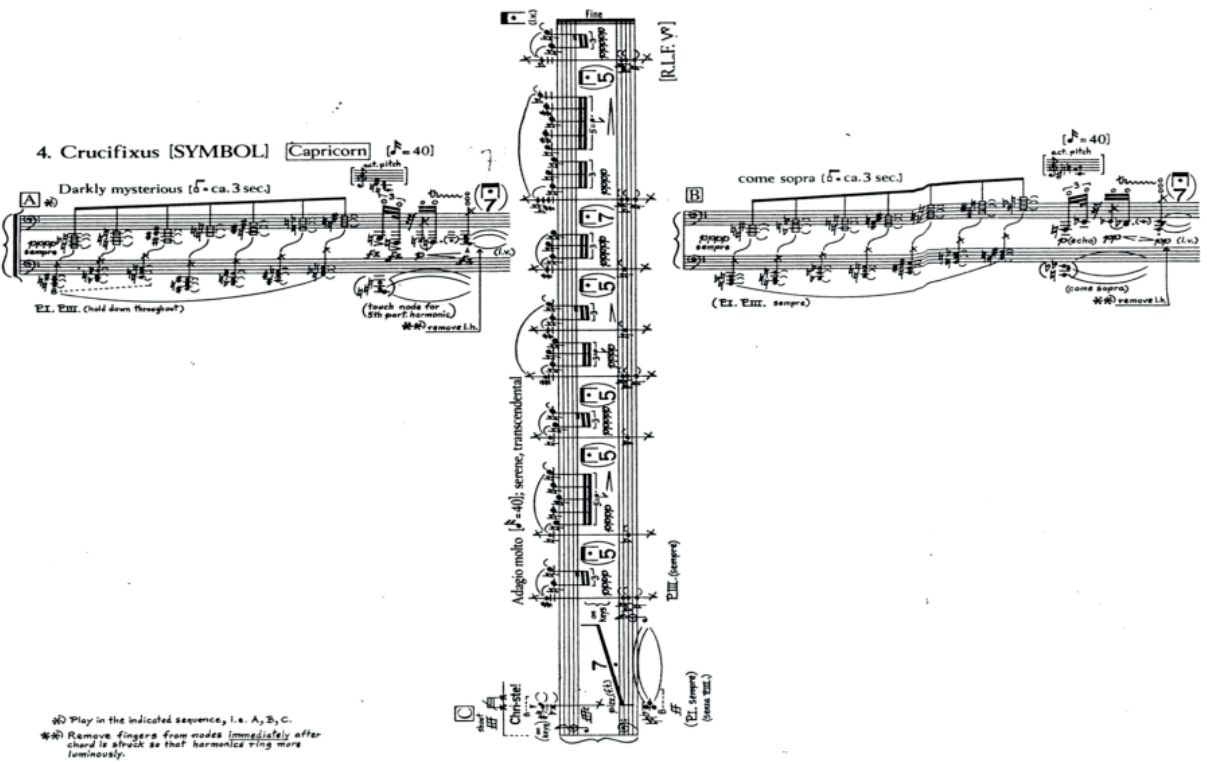

Şekil 3. Sembolik Notasyon (Crumb, 1974, s. 10)

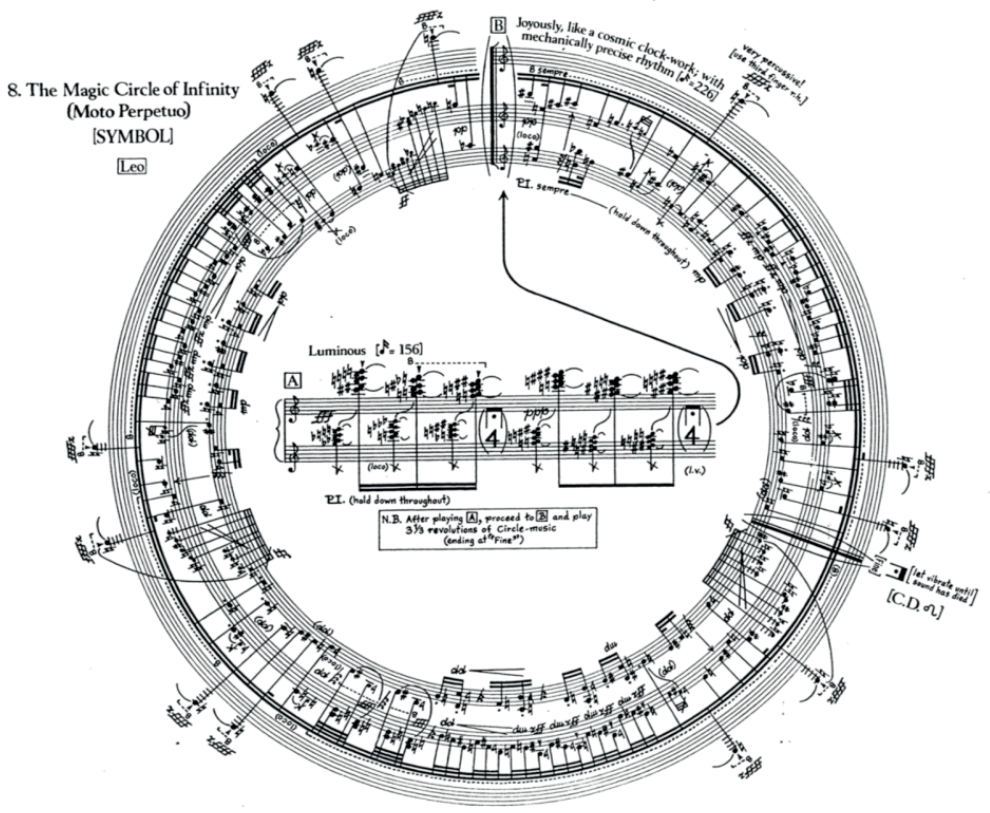

Şekil 4. Sembolik Notasyon (Crumb, 1974, s. 14) 
2 ve 10 numaralı parçalarda besteci kromatik diziler kullanmıştır; Şekil 3’te görüldüğü gibi 1.2. ve 3. bölümlerin son parçalarında sembolik notasyon bulunmaktadır.

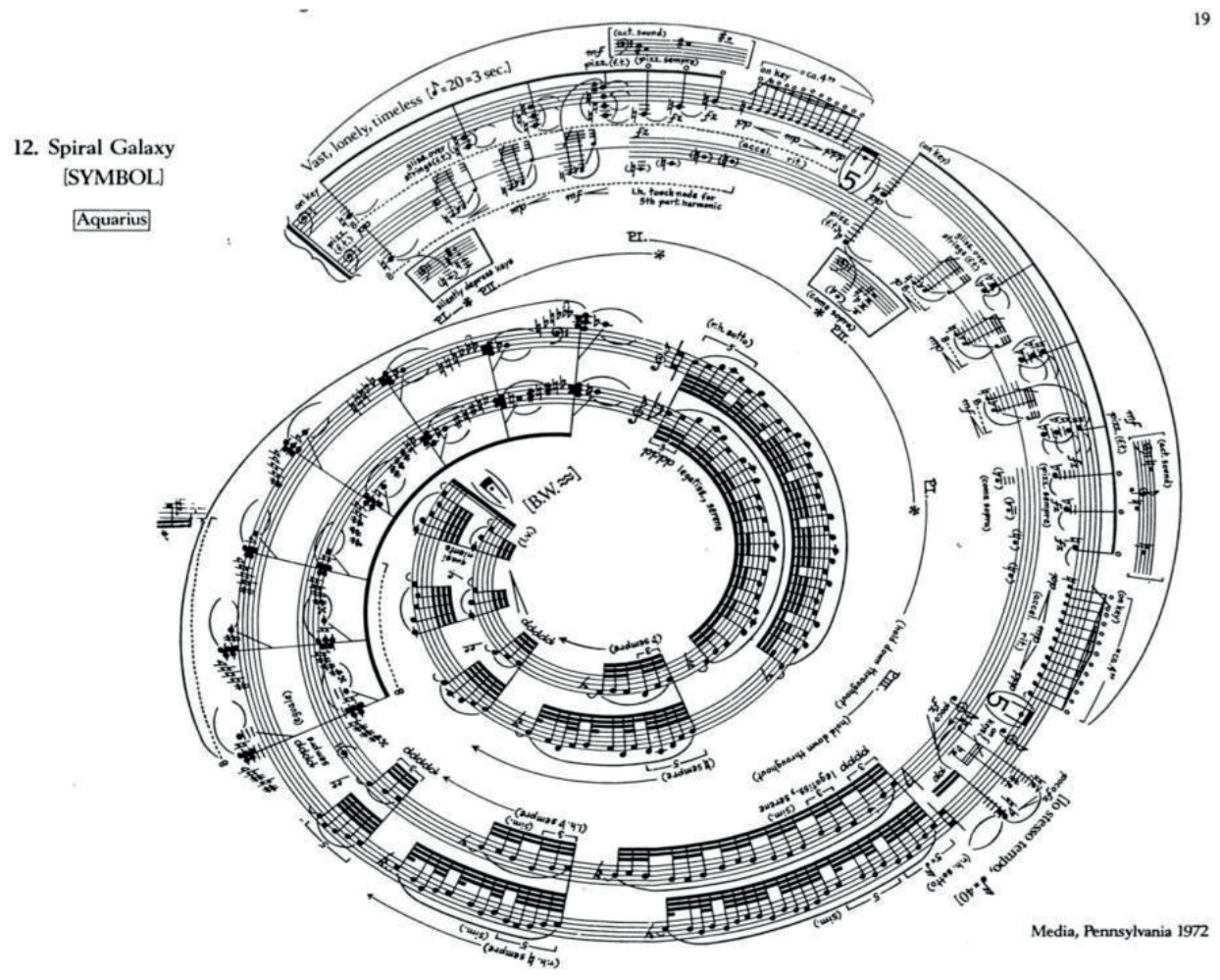

Şekil 5. Sembolik Notasyon (Crumb, 1974, s. 19)

Şekil 6'da görüldüğü üzere; 1., 4. ve 9. parçalar aynı akorlarla başlamaktadır, ilk ve son parçalarda ise 13 ve 14 notadan oluşan repetisyonlar vardır. 1 numaralı parça zincir, 5 numaralı parça yüksük ve 9 numaralı parça pena olmak üzere; Crumb, her 3 bölümün başında yeni bir materyal ile piyanonun içinde çalınmasını istemiştir (Bass, 1991, s. 13). 

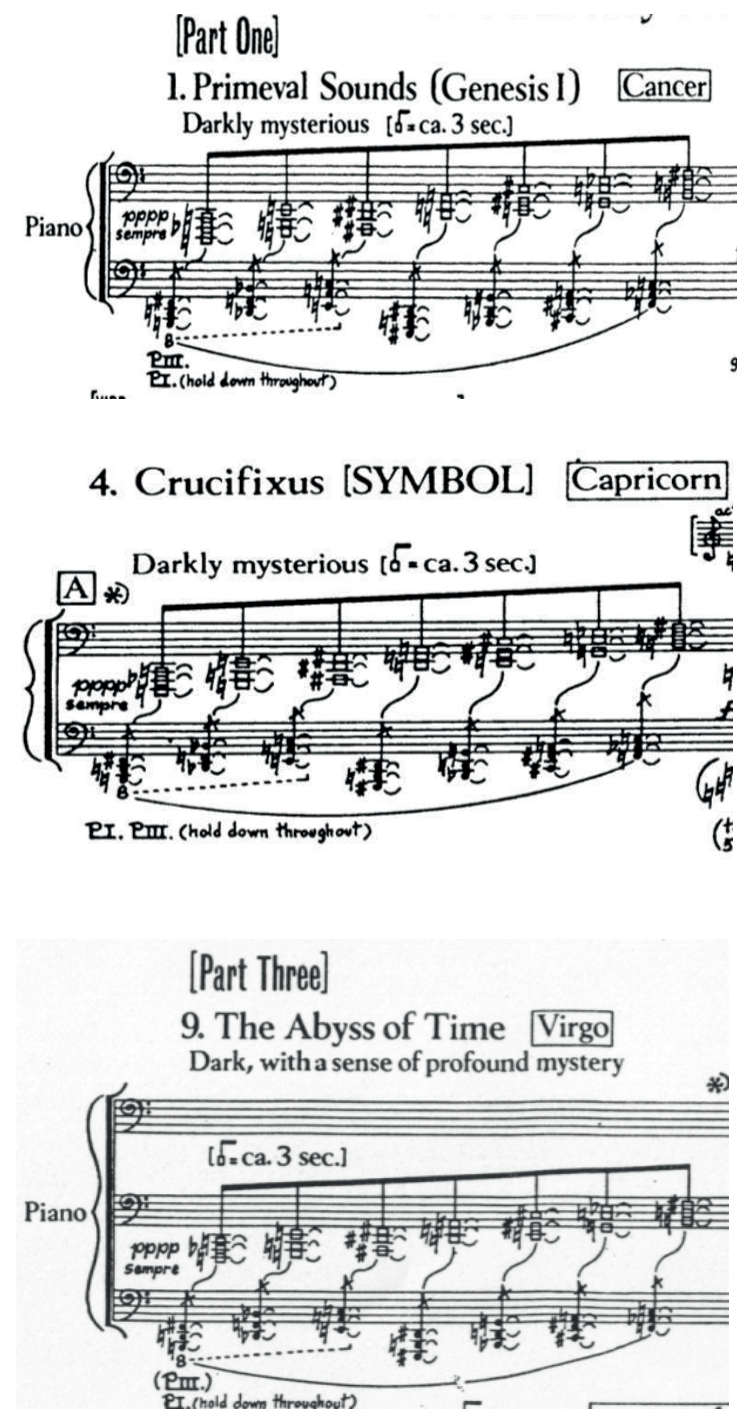

Şekil 6. 1., 4. ve 9. parçaların başlangıçlarında yer alan aynı akorlar

(Crumb, 1974, s. 6,10,15)

\section{Gelişmiş Piyano Teknikleri}

Gelişmiş piyano teknikleri, piyanonun bir enstrüman olarak yalnızca tuşları vasıtasıyla çıkarılan seslere ek olarak iç ve dış aksamını, tellerini, ses tahtasını, çelik ve ahşap kısımlarını da içerecek biçimde; çeşitli obje ve materyalleri, hatta insan sesini de kullanarak 
çalınması tekniğidir. 20. yüzyılın ilk yarısından itibaren giderek yaygınlık kazanan bu teknikle bestelenen birçok eser bulunmaktadır. Gelişmiş piyano teknikleri geçtiğimiz yüzyıl ve içinde bulunduğumuz yüzyılda Henry Cowell, Karl Heinz Stockhausen, John Cage, Sofia Gubaidulina gibi yeni tınılar ve notasyon teknikleri arayan pek çok besteci tarafından kullanılmaktadır (Vaes, 2009). Makalenin bu bölümünde 20. yüzyıl piyano repertuvarında önemli bir yeri olan Makrokosmos I (Crumb, 1974) eserinde kullanılan, pizzicato, telleri susturarak çalma, glissandolar, doğuşkanlar, ses tahtasından çıkarılan perküsif efektler, zincir, yüksük, pena gibi çeşitli materyaller, sslık ve vokal efektleri gibi gelişmiş piyano teknikleri incelenmektedir. Bu tekniklerin icrası sırasında karşılaşılabilecek sorunların çözülmesine dair öneriler ve dikkat edilmesinin önemli olduğu düşünülen çeşitli pratik bilgiler aktarılmaktadır.

\section{Pizzicato ve Doğuşkanlar}

Eserin icrası sırasında üç çeşit pizzicato kullanılmaktadır: Bunlar parmak ucuyla, tırnakla telin çekilmesiyle ve telin bir el tarafından susturulurken diğer elin teli çekmesi suretiyle doğuşkanların çıkarılması şeklinde uygulanmaktadır. Parmak ucu ile olanlar, 'f.t.' olarak gösterilmekte ve telin rahat titreşebileceği yer olan orta noktasından çekilmektedir. Sıcak bir tonu volan bu sesi piyanistin bestecinin istediği şekilde çıkarabilmesi için uygulayacağı baskıyı iyi tahayyül etmesi gerekmektedir. Bu anlamda her enstrümanda bu efekt farklı olabileceği için, eserin seslendirileceği salon ve piyanoda çalışılmasının faydalı olacağı düşünülmektedir.

Tırnak pizzicatoları, 'f.n.' olarak gösterilmekte; telin akor çivilerine yakın olan kısmından yapılmaktadır. Çınlayan ve pırıltılı bir ses çıkarmaktadır. Makrokosmos 6 numara 'Night Spell' bölümünde, Bartok'un Out of Doors Süiti'ndeki The Night's Music ile kurduğu t1nısal ilişkiyi açıkça görebiliriz. Buradaki gece efekti sağ pedalın parçanın başından sonuna kadar basılı kalmasıyla, teller üzerindeki pizzicatolar, ıslık efektleri ve bestecinin keskin bir şekilde notasyonla gösterdiği piyanonun içine vurmak suretiyle çıkarılan yankılar sayesinde yakalanmaktadır. Makrokosmos 6. Night Spell ve 5.The Phantom Gondolier'de hem tırnak (f.n.) hem de parmak ucu (f.t.) pizzicatoları sıklıkla bulunmaktadır. Besteci Performance Notes'ta iki ayrı pizzicato tekniğinin nasıl çalınması gerektiğini detaylarıyla anlatır (Crumb, 1974, s. 5). Bu pizzicatolardan parmak ucu ile olanının tellerin ortasından, tırnakla yapılanın ise akor çivilerine yakın kısımdan yapılması gerekliliğinden ötürü, bu hareketin önceden planlamas1 gerekmektedir (Matthews, 1981, s. 81). 


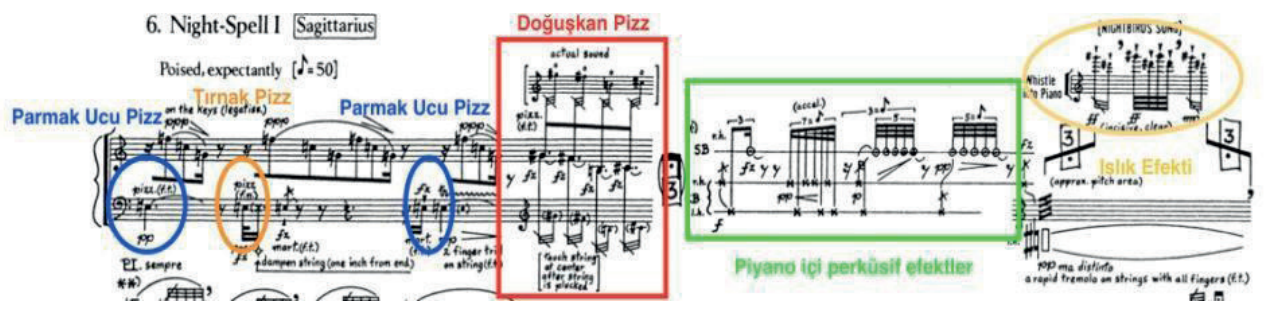

Şekil 7. Gece efekti (Crumb, 1974 s. 12)

12. Spiral Galaxy'deki pizzicato ilginç bir zorluk seviyesi taşımaktadır; çünkü parçanın ilk notasıdır ve mümkünse yerinin ezberlenmesi önerilmektedir. Yanlış çalındığında parça boyunca uzamaya devam edeceği için icra sırasında göze batma ihtimalinden kaçınmak gerekmektedir (Matthews, 1981, s. 83).

Parmak ucu ve doğuşkan pizzicatoları ise 'o' ya da 2nd partial node olarak gösterilmektedir. Çok alış1lagelmiş bir teknik olmayan bu pizzicatoyu gerektiği gibi gerçekleştirmek için özenli bir çalışmanın gerekliliği söz konusudur.

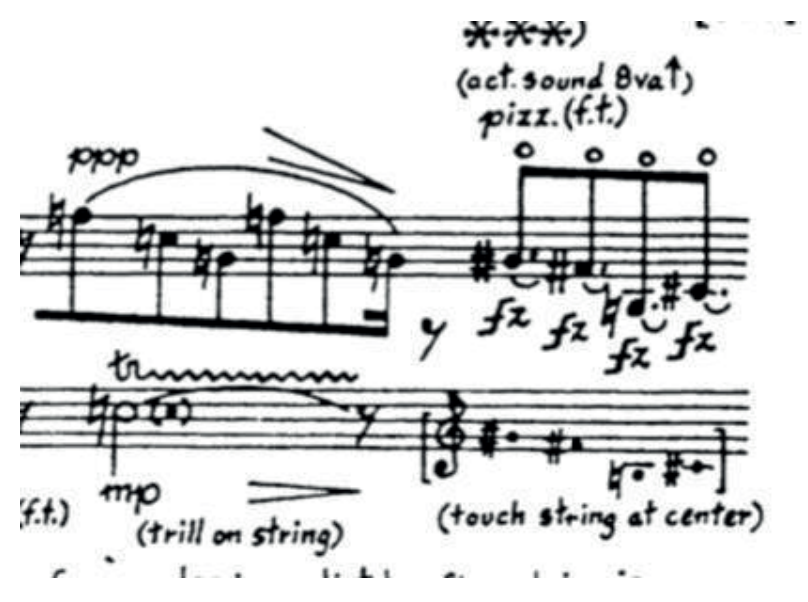

Şekil 8. Night-Spell Doğuşkan pizzicato (Crumb, 1974 s.12)

Bu efekt, sol el teli sustururken diğer elin teli çekmesi (pizzicato çalması) ve aynı anda teli tutan sol elin teli birakmasıyla mümkün olmaktadır. Arpistlerin tek el ile rahatlıkla çıkarabildikleri bu efektin piyanoda da aynı teknikten faydalanarak çıkarılabileceği ma- 
kale yazarının kendi çalışmaları sırasında deneyimlenmiştir ${ }^{4}$. Sağ el baş parmak ve avuç içiyle teli sustururken, aynı zamanda ikinci parmak ile teli çekip, elin telden uzaklaştırmasıyla yakalanabilecek bu teknik, bestecinin önerisinin aksine, biraz çalışma sayesinde tek el ile daha rahat uygulanabilir olduğu düşünülmektedir. 4. Crucifixus bölümünün başında bulunan doğuşkanlar, sol elin telleri bastırırken sağ elin si-fa-sol tuşlarını çalmasıyla elde edilmektedir. Bu doğuşkanları doğru çalmak çok önem taşımaktadır; çünkü parça boyunca tınlamaya devam etmektedirler (Burge, 1976, s. 100).

Bir diğer doğuşkan tınısı ise metal penanın tellere sürtülmesi ve diğer elin tellerdeki işaretlenmiş doğuşkan bölümlerine dokunması ile gerçekleşmektedir. Makrokosmos I; pizzicato, susturulmuş notalar ve doğuşkanların çıkarılması gibi çeşitli özel teknikler gerektirmektedir. Bu efektleri doğru şekilde icra edebilmek için, tellerin yapıştırıcı bant ile işaretlenmesi gerekmektedir. Aşağıda yer alan Şekil 9 özellikle işaretlenmesi gereken notaları göstermektedir. Doğuşkanları çıkarabilmek için gereken kesin noktaların küçük bir yapıştırıcı bant ile gösterilmesi mümkündür. Bu şekilde işaretlenen teller, Crumb'ın (1974) belirttiği şekilde 'B' ile işaretlenebilir. A ile işaretlenenler 5th partial, B ile işaretlenenler 2nd partial doğuşkanlardır. Şekil 7'de gösterildiği gibi, piyanistler tarafından tercih edilen başka bir yöntem ise, tüm siyah tuşların işaretlenmesidir (Crumb, 1974).

\section{Telleri Susturarak Çıkarılan Sesler}

Makrokosmos, 1. Primeval Sounds ve 9. The Abyss of Time'da tellerin başladığı yerden 2,5 santimetre (akord çivileri ve çekiçlerin ortasında) ilerisinden başlayan kısmı sol el ile susturularak, sağ el ile tuşlarla çalınmaktadır. Besteci burada yorumcuya doğru telleri bulabilmek için gereken zamanı tanımaktadır. Tuşlara kısmen basılarak çekiçlerin tele dokunmadan hafifçe hareket etmesiyle doğru tel bulunabilir. Önceden susturucuları işaretlemek faydalı olsa da bu teknik tel ve susturucular arasında göz yanılmasına neden olabileceği için çekiçlerin denk geldiği teli bulmak daha kolay olmaktadır. Besteci giriş notlarında tuşları işaretleme konusunda çeşitli açılamalarda bulunmuştur (Bkz. Crumb, 1974).

4 Yazarın İstanbul CKM'de 21 Mayıs 2017 tarihinde verdiği solo piyano resitalinde Crumb'ın Makrokosmos I eserinde Night Spell'i seslendirdiği konser kaydına https://www.youtube.com/watch?v=JTHgeKuGrVs\&ab_ channel=redbaris linkinden ulaşılabilir. 


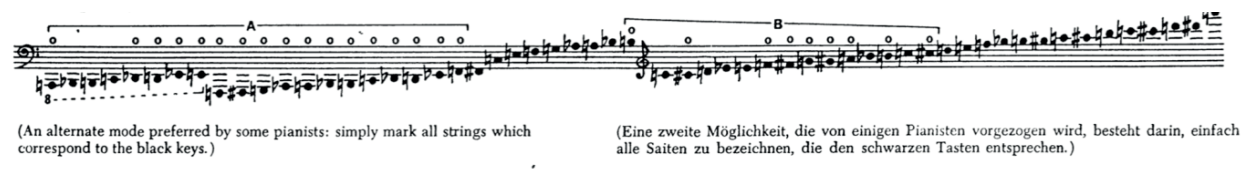

Şekil 9. Performance Notes (Crumb, 1974 s.5)

\section{Glissandolar}

Makrokosmos'ta tuşlar ve teller üzerinden yapılan glissandolara sıklıkla rastlanmaktadır. Bazen tuşlara sessizce basılı tutularak teller üzerinde yapılan gliassandolar akorların doğuşkanlarına çözünürler (Matthews, 1981, s. 93). Tel üstünde yapılan glissandolar, parmak ucuyla 'f.t.', tırnak ile olanlar 'f.n.' şeklinde gösterilmektedir. Crumb (1974), Makrokosmos II'nin Performance Notes kısmında glissandoların nasıl çalınması gerektiği konusunda daha kapsamlı bilgi vermektedir. "Teller pedal susturucularının önünden, akor çivileri ve çelik bağlantının arasından çalınmalıdır, (ya da pedal susturucularının arkasından) tınısal ve performans kolaylığı faktörleri konusunda seçim hakkı piyaniste bırakılmıştır. Glissandoların kesin mesafeleri belli edilmiştir" (Crumb, 1974, s.74).

1. Primeval Sounds ve 5. Phantom Gondolier' de glissandolar, 'La 0-Re Diyez 3' arasinda bulunmaktadır. Farklı marka ve boyuttaki piyanolarda çelik kasaları ve tel geçişleri de farklı inşa edilmiş olduğundan, özellikle 7. Music of Shadows'ta bazı sorunlar yaşanmasının mümkün olduğu gözlemlenmiştir. Burada sessizce bastırılan akorların dairesel şekilde glissandolarla çalınması gerekmekte; bazı enstrümanlarda ise bu akorlar çelik geçişlerle bölünmüş olduğundan icracının çalma sürekliliğini etkilemesinin mümkün olduğu belirtilmektedir. Bu soruna Burge, pratik bir çözüm getirerek akorların sostenuto pedalıyla emniyete alındıktan sonra glissandonun iki ele bölünerek çalınması önerisini sunmuştur (Burge, 1976, s. 20). Bestecinin eseri yazdığı piyano, 'Steinway L model' olduğundan eserin en rahat seslendirileceği enstrümanlardan birinin bu model bir piyano veya 'Steinway D model' olduğu düşünülmektedir.

\section{Objeler}

Zincir kolye, 1 numarada bas tellerin üzerine yerleştirilmekte ve parçanın bitişine kadar orada bırakılmaktadır. Crumb (1974), eserin Performance Notes kısmında hafif ve alü- 
minyum bir kolye kullanılmasını ve iki ucunun metal kasaya bağlanarak kullanılmadığı zamanlarda bir ucunun akor çivilerine geçirilmesini önermektedir.

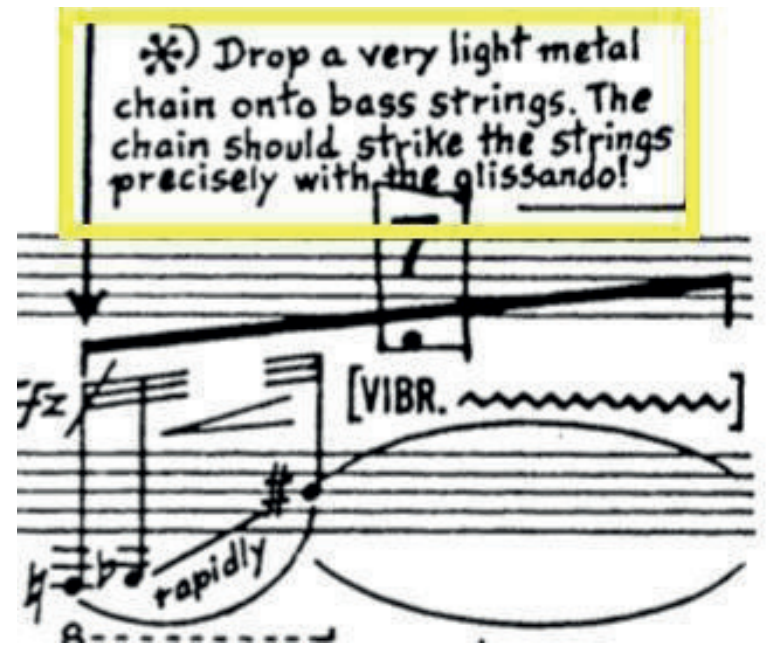

Şekil 11. Zincir Kolye (Crumb, 1974 s.6)

Bu konuyla ilgili deneyimlenen ve faydalı bulunan diğer bir teknik ise, kolyenin bir ucunun piyanonun sağ tarafına bantlanmasıdır. Böylelikle 2 numaralı parçaya geçerken, kolyenin piyanodan çıkarılmasıyla meydana gelebilecek seslerin önlenebilmesi mümkün kılınmaktadır. Bir başka öneri ise; gerekli durumlarda zinciri koymak üzere, üstünde bir havlu bulunan nota sehpasının piyanonun yanına yerleştirilmesi ve böylelikle istenmeyen seslerin engellenmesidir. Buradaki zincir/kolye seçimi önem taşımaktadır; eğer zincir ağır olursa aralıklı olan pes tellerinin arasına düşecek ve piyanoya zarar vermenin yanı sıra gürültülü sesler çıkarma olasılığı taşımaktadır. Bu yüzden seçilecek zincirin ağırlığına dikkat etmek gerekmektedir. Zincirin bir ucundan piyanoya, diğer ucundan da akor çivilerine bantlanması; pes tellerin titreşiminden dolayı serbest kalıp tellerin arasına düşmesini engellemektedir. Böylelikle piyanoya zarar verebilecek olan zincirin kontrolsüz hareketi ve düşmesi engellenmiş olmaktadır (Matthews, 1981, s. 104). 5 numarada Crumb, sağ elin ikinci ve üçüncü parmaklarına yüksük takılmasını istemektedir (Şekil 12). Bas rejisterlerde gıcırdatarak çıkarılan sesler, telleri vurarak ve tel üstünde yapılan triller, yüksük teknikleri arasında yer almaktadır. Crumb kendi açıklamalarında bunu detaylı olarak şöyle anlatmaktadır; "Teller parmak ucuna takılan yüksüklerle kazınarak (sürtülerek) ya da sert şekilde vurularak çalınır. Trillerin 
doğru uygulanabilmesi için başparmağa giyilen ekstra bir yüksük kullanılabilir" (Crumb, 1974, s. 5).

Şekil 13’te görüldüğü üzere; Metal Plectrum (metal pena) piyaniste doğru yavaş yavaş çekilerek bas teller üzerinde sert, rendeleyici bir efekt çıkartılmaktadır. Bunun dışında hızlıca piyanonun içine doğru kaydırarak kısa ve iç gıcıklatan bir ses ve ileri geri hareketlerle çıkartılan tremolo efekti pena ile çıkartılan efektler arasında yer almkatadır. Burada Crumb'ın önerdiği metal pena kolaylıkla edinilebilecek bir nesne olmadığı için performans notlarında öneri olarak orta boy bir atacın da kullanılabileceğini belirtmesi icracılar açısından kolaylık sunmaktadır (Crumb, 1974, s. 5).

\section{The Phantom Gondolier Scorpio} Eerilv. with a sense of malignant evil $[\delta=60]$ uc we.e? [The forrennger and middle finger of right hand should be fitted with metal thimbles]

Şekil 12. Yüksük (Crumb, 1974 s.11)

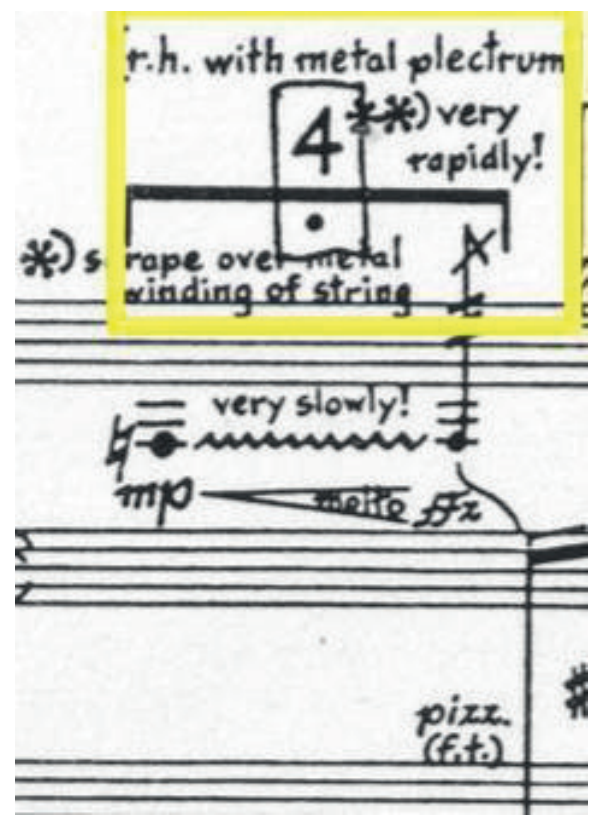

Şekil 13. Metal Pena (Crumb, 1974 s.15) 


\section{Vokal Efektler}

Makrokosmos, çeşitli vokal efektler ve ıslık çalmayı gerektirmektedir. Fisıldama, inleme, bağırma, şarkı söyleme, rüzgâr sesi ve hatta hayalet inilteleri de bunlara dahildir. Bütün vokal efektler fa anahtarında notaya alınmıştır. Eserdeki ilk vokal efekt, 4 numarada seyirciyi şaşırtan, piyanistin bağırarak söylediği 'Christe' ile gelmeketedir. Yankıları 7 saniye sürmketedir. Tüm vokal efektlerin dramatik ve ikna edici olması iyi bir performansın önemli yanlarından biri olabilir. 5. Phantom Gondolier' deki kromatik 'ah' vokalleri Crumb'ın detaylı ifadesiyle macabre obscene $e^{5}$ bir şekilde söylenmesi gerekmektedir.

Parçanın tiyatral yapısını ortaya çıkaran bu efektleri ayrı olarak çalışmanın faydalı olduğu düşünülmektedir. Vokal efektlerin performans esnasında yüksek ses, doğru artikülasyon, ifade ile anlaşılabilir ve ikna edici bir şekilde gerçekleştirilmesi gerekmektedir. Bu sebeple eserin çalışılması sırasında oyuncu ve rejisör meslektaşlarımızdan yardım almak yerinde olacaktır. Özellikle yirminci yüzyıl repertuvarına çok fazla ilgi duymayan ve benzer eserleri icra etmemiş piyanistler için efektlerin eserin seslendirileceği salonda denenmesi bu açıdan faydalı görülmektedir. Bu konu ile ilgili olarak 9 numaradaki rüzgâr sesi efekti hakkında besteci şöyle demektedir: "Pür rüzgâr sesi için iki sese ihtiyaç vardır 'ş' ve ' $w$ '. Bu seslere bir 'w-f' efekti eklemek seslerin yansıtılmasına yardımcı olacaktır. Yorumcuların konuşulan, fisıldanan ve bağırılan mesajları temiz ve anlaşılır bir şekilde seyirciye duyurmaları önemlidir. $\mathrm{Bu}$ efektlerin nüansları salonun akustiğine göre abartılabilir” (Crumb, 1971, s. 3).

6. Night-Spell' de ilk ıslık çalma efekti karşımıza çıkmaktadır. Bu efekt Crumb'ın başka müziklerden alıntılarına çok iyi bir örnek olmasının yanısıra; pizzicatolar Re Pentatonik gamından çalınırken ıslıkla çalınan bir ilahi olan ‘Will There Be Any Stars In My Crown' Re Bemol Majör tonunda bulunmaktadır. Eserin çalışılması sırasında bu efekt, zorluk derecesi yüksek olsa da birkaç prova ile rahatlıkla uygulanabildiği görülmektedir. Islık efektlerini duyurabilmek için doğru şekilde nefes almak oldukça önem taşımaktadır. Islık sesinden çıkan havanın sesinin de mikrofona yapılan ıslık sesiyle beraber yükselme ihtimali taşımasından dolayı, bu efektin mikrofona doğru direkt olarak uygulanmamasının daha uygun olduğu düşünülmektedir.

\section{Enstrümanlar Üzerine}

Pek çok konser salonunda bulunan Steinway D model, Makrokosmos I için uygun bir piyanodur. Bu enstrümanın içinde sadece taşınırken lazım olan orta çelik bağlantıyı kal-

5 Macabre obscene Fr.-Ing. Crumb'ın bahsettiği biçimiyle eserde tariflediği vokal efektinde ölümü andıran, ürkütücü, dehşetengiz ve aynı zamanda müstehcen bir biçimde söylemek anlamında kullanılmaktadır (Crumb, 1974). 
dırdığımızda eseri seslendirmek çok daha kolay olmaktadır. Her marka ve modelde çelik bağlantılar ve tel uzunlukları değişeceği için eserin icrasına uygun olarak bazı ayarlamalar yapmak gerekmektedir. Örneğin, Steinway D Model piyanolarda doğuşkan sesleri çıkarmak için tellere doğru uzanılması gereken mesafeler uzadığından dolayı fa telindeki 5. bölüm doğuşkanın karşıllı̆ı olan re telinin 3. bölüm doğuşkanına eş olduğu için bu şekilde de çıkartılabileceği bilinmektedir.

Ayrıca sostenuto pedalı, eser için büyük önem arz etmektedir. 2 numaralı parçayı bu pedal olmadan seslendirmek mümkün olmayacaktır. Bu parçada ön kollar kullanılarak pest rejisterdeki sesler; tuşlar ses çıkartmadan pedala alınarak parça boyunca bir yankı efekti oluşmaktadır. Sağ eldeki kısa notalara karşıt olarak çıkan bu efekt, sostenuto pedalı olmadan gerçekleşmemektedir. Bu yüzden konser salonunda prova yapılırken pedalın gerektiği gibi çalıştığının kontrol edilmesi önerilmektedir.

Piyanonun susturucuları ve tellerinin bazılarını işaretlemek de faydalı bulunmaktadır. Yorumcunun bu işaretlemeyi yaparken piyanoya zarar vermemeye dikkat etmesi önerilmektedir. "Susturucu ve telleri hızlıca işaretleyip kolayca çıkarabilmek gereklidir" (Burge, 1976, s.20). Susturucuların üzerindeki işaretler notaları, tellerin üzerindekiler ise doğuşkanlanı göstermektedir. Kullanılacak işaretleme malzemesinin kolaylıkla yapışıp sökülecek şekilde seçilmesi önerilmektedir. Örneğin Post-it gibi kendinden yapışkanlı malzemeler kolaylıkla yapışıp performans sonrası sökülebildiği için kullanılabilirler. Fakat susturuculardan çıkarılamayacak olan malzemelerin kullanımı önerilmemektedir. Yorumcunun telleri ve susturucuları mümkün olduğunca kısa süre içerisinde işaretleyip zarar vermeden konser salonundan ayrılabileceği bir düzenek geliştirmesinin faydalı olacağı düşünülmektedir. Crumb kendi işaretleme seçimlerini giriş ve açıklama bölümlerinde göstermiş olmasına rağmen yine de farklı işaretleme tekniklerinin kullanımının yorumcunun tercihlerine göre farklılık göstermesi mümkün olabilmektedir. Çelik bağlantıların hangi notalara denk geldiğini ezberlenip, seslerin nerelerde olduğu hakkında genel bir fikir sahibi olunması önerilmektedir (Matthews, 1981, s. 136). Tekli, çiftli ve üçlü tellerin kesişme noktalarının hatırlanması ve bu şekilde seslerin bulunması da kolaylaşabilmektedir. Besteci, doğuşkanlar için tellere küçük bir yapıştırıcı bant bağlamayı önerse de bu genel olarak telin sesini biraz değiş̧tirebileceğinden ötürü özenli uygulanması gerekmektedir. Örneğin yapıştırıcı yerine kullanılacak bir oje ile de bu noktaların işaretlenebilmesi mümkündür. Bu işlem yapılırken ojenin oldukça dikkatli bir şekilde sürülmesi ve ses tahtasına akarak deforme etmemesine özen gösterilmesi önerilmektedir. Ayrıca tebeşir ve pastel gibi malzemeler kullanılarak bu işaretlemelerin 
gerçekleştirilmesi mümkündür. Crumb, Makrokosmos Volume II'de işaretleme için pastel kullanılmasını performans notlarına eklemiştir (Crumb, 1974). Yine de tebeşirin ses tahtasına dökülmesi olasılığından dolayı gazlı kalemler ya da oje gibi kolay çıkmayan malzemelerin kullanımının daha iyi sonuç verdiği düşünülmektedir.

\section{Amplifikasyon}

Crumb (1974), Performance Notes'ta, yaygin olarak kullanılan bir mikrofonun bas telleri üzerine doğru sarkıtılarak kullanılmasını önermektedir. Amplifikasyon seviyesinin epeyce yüksek olmasının, yüksek pasajlarda kuvvetli etki yaratacağını ve ses seviyesinin performans sırasında değiştirilmemesi gerektiğini söylemektedir. Bu efekt genellikle bir mikrofon ve piyanonun sağ ve soluna yerleştirilen iki hoparlör ile sağlanmaktadır. Amplifikasyon makale boyunca bahsedilen tüm gelişmiş tekniklerin duyulmasına yardımcı olmaktadır. 7-13 saniye gibi uzun boşluklarda bile sesin devam etmesini ve bu egzantrik seslerin uzamasını sağlamaktadır. Özellikle yüksek olmayan efektlerin yeterli şekilde duyulması için, eserin çalınacağı salonda bir ses mühendisi ya da meslektaşın yardımı alınarak ilgili kontrollerin yapılması önerilmektedir. Aynı şekilde yüksek seslerin seviyesinin hoparlörlere aşırı yüklenme yapmayacak seviyede tutulmasına özen göstermek gerekmektedir.

\section{Sonuç}

Bu makalede George Crumb'ın Makrokosmos I eserinin 'gelişmiş piyano teknikleri' kullanımı detaylı biçimde incelenerek; bestecinin performans notları, etkilendiği eserler ve kişisel deneyimlere dayalı olarak değerlendirilmiş; nitelikli bir performans için dikkat edilmesi gerektiği düşünülen hususlar açıklanmıştır. Bu bağlamda performansın nitelikli olabilmesi için sadece notaların doğru icrasının yeterli olmadığı, ilgili teknik hususların da giderilmesi gerektiği gözlemlere dayalı olarak aktarılmıştır. Özellikle piyanonun bütüncül aksamına eşlenik olarak vokal efektlerinin olması, eserin icrasında farklı çalışma ve işaretleme tekniklerinin geliştirilmesinin gerekliliğini ortaya koymaktadır. Bu konuda eserin bestecisinin yorumları dışında, yazıldığı piyanist olan Burge'ün deneyimleri ve pratik edilen yöntemler açıklanmıştır. 20. yüzyıl bestecilerinin en önemlilerinden biri olan Crumb'ın bu eserinin hem sembolik etkileşimi hem de notasyona aktardığı analizler ele alınmış; yapılan analizlerle icracılar için eserin kavranmasına yönelik kolaylıklar sunmak amaçlanmıştır. Eserin içinde yer alan tiyatral efektleri ayrı olarak çalışmanın faydalı olduğu düşünülmekte, bu efektlerin performans esnasında yüksek ses, doğru artikülasyon, doğru ifade ile anlaşılabilir ve ikna edici bir şekilde gerçekleştirilmesi gerek- 
tiği, bu sebeple çalışılması sırasında oyuncu ve rejisör meslektaşlarımızdan yardım almanın faydası açıklanmaktadır. Yine aynı şekilde konser salonunda mikrofon ve hoparlörün yüksek sesleri doğru biçimde yansıtması için ilgili kontrollerin yapılmasının önemli olduğu belirtilmiştir. Pratik bilgiler olarak işaretleme ve gelişmiş piyano tekniklerinde kullanılan tekniklerin uygulanması, seçilecek malzeme, obje ve araçlarla ilgili yöntem ve öneriler açıklanmıştır.

\author{
Hakem Değerlendirmesi: Dış bağımsız. \\ Çıkar Çatışması: Yazar çıkar çatışması bildirmemiştir. \\ Finansal Destek: Yazar bu çalıșma için finansal destek almadığını beyan etmiştir. \\ Peer-review: Externally peer-reviewed. \\ Conflict of Interest: The author has no conflict of interest to declare. \\ Grant Support: The author declared that this study has received no financial support.
}

\title{
Kaynakça/References
}

Bass, R. (1991). Set, Scales and Symmetries: The Pitch Structural Basis of George Crumb Makrokosmos I and II. Music Theory Spectrum, Volume 13, No: 1, 1-20. Erişim adresi: http://www.jstor.org/stable/745971

Burge, D. (1990). Twentieth Century Piano Music. New York: Schirmer Books.

Burge, D. (1976). Performing The Piano Music Of George Crumb. Contemporary Keyboard, II/4, 20-21. Erişim adresi: https://core.ac.uk/download/pdf/215269034.pdf

Cohen, D. (2002). George Crumb A Bio-Bibliography, Bio-bibliographies in Music. London, Westport, Connecticut: Greenwood Publishing Group.

Crumb, G. (1974). Makrokosmos, Volume I-II for Amplified Piano. New york: C.F. Peters.

Crumb, G. (1971). Songs, Drones and Refrains of Death. Newyork: C.F. Peters.

Crumb, G. (1974). George Crumb Makrokosmos Volume I, Notes for Vinyl Record. Kaliforniya, Nonesuch Records.

Duffie, B. (1998). Interview with George Crumb, "Composer George Crumb", A Conversation with Bruce Duffie, WNIB, Classical 97. Chicago, Erişim adresi: http://www.bruceduffie.com/crumb2.html

Hanehan, D. (1975, Mayıs 11). Crumb, The Tone Poet. The New York Times. Erişim adresi: https:/www.nytimes. com/1975/05/11/archives/crumb-the-tone-poet-crumb.html

Matthews, N. W. (1981). George Crumb's Makrokosmos Volume I and II: Considerations for performance, Including Observations by David Burge, Robert Miller and Lambert Orkis (Doktora tezi, University of Oklahoma School of Music, Norman). Erişim adresi: https://core.ac.uk/download/pdf/215269034.pdf

Pearsall, E. (2004). Symmetry and Goal Directed Motion In Music By Bela Bartok And George Crumb. Tempo 58, 228, 32-40. doi: 10.1017/S0040298204000129

Shuffett, R. (1979). The Music, 1971-75, of George Crumb: A Style Analysis. Erişim adresi: https://books.google. com.tr/books

Vaes, L. P. F. (2009). Extended Piano Techniques: in theory, history and performance practice (Doktora tezi, Faculty of Humanities, Leiden Üniversitesi, Leiden). Erişim Adresi: https://openaccess.leidenuniv.nl/handle/1887/15093 